\section{The subunit story thickens}

\section{R. J. Lefkowitz}

THE heterotrimeric $\mathrm{G}$ proteins ${ }^{1}$, molecules that have a central role in signal transduction across the cell membrane, are composed of $\alpha, \beta$ and $\gamma$ subunits. For several years it was the $\alpha$ subunit which held the limelight, with a great deal of attention being paid to its mediation of the activation of an ever-growing list of effector molecules such as enzymes and ion channels. The $\beta$ and $\gamma$ subunits, by contrast, were held to be the dull end of $\mathrm{G}$ proteins, serving merely to regulate the levels of the uncomplexed, active $\alpha$ subunit. That dogma has come increasingly into question through, for example, reports in Science ${ }^{2}$ late in 1991 and in Nature ${ }^{3}$ earlier this year. Even more excitingly, we now have the report by Kleuss et al., on page 424 of this issue $^{4}$, which shows that specific $\beta$ subunits are involved in coupling specific receptors to a calcium channel.

The $G$ proteins were initially discovered as integral components of the adenylyl cyclase ${ }^{5}$ and retinal phototransduction ${ }^{6}$ systems, and were named after the characteristic property of their $\alpha$-subunits, the ability to bind and hydrolyse guanine nucleotides. The other two subunits were discovered subsequently; they form a tightly associated complex, being dissociated only under denaturing conditions.

For all the attraction of the $\alpha$-subunit, by 1989 prominent roles for $\beta \gamma$ in carrying receptor-derived information in several transmembrane signal transduction systems had begun to emerge (for example, pheromone-induced mating in Saccharomyces cerevisiae and, perhaps less convincingly, activation of $\mathrm{PLA}_{2}$ (reviewed in ref. 7)). Experiments from two laboratories have now called into question what had seemed to be the very well-established solo role of $\alpha$ in activating adenylyl cyclase $\mathrm{e}^{2,3}$. Gilman and colleagues cloned several distinct forms of this enzyme (currently referred to as types I-IV (refs 8-11) with more reportedly on the way). Tang and Gilman ${ }^{2}$ expressed several forms of these enzymes in SF9 cells by infection with recombinant bacculovirus and then examined their in vitro regulation by $\alpha$ and $\beta \gamma$-subunits of $\mathrm{G}_{\mathrm{s}}$. Results with the type I adenylyl cyclase (which is a $\mathrm{Ca}^{2+}$ / calmodulin-sensitive form) were pretty much as predicted $-\alpha_{\mathrm{s}}$ stimulates and $\beta \gamma$ inhibits, presumably by complexing activated $\alpha_{\mathrm{s}}$ because, by itself, $\beta \gamma$ has no effect. Results for the type II enzyme, however, were strikingly and surprisingly different. This form of the enzyme (which is $\mathrm{Ca}^{2+} /$ calmodulin-insensitive) was stimulated to the same extent as the type I by $\alpha_{\text {s }}$, but was also strikingly stimulated by $\beta \gamma$ in the presence of activated $\alpha_{\mathrm{s}}$. Type III adenylyl cyclase showed relatively little sensitivity to $\beta \gamma$, and type IV was similar to type II in its properties $^{11}$.

Federman et al. ${ }^{3}$ essentially confirmed these findings, but they used a novel approach which immediately suggests the relevance of the new findings to receptor-mediated transmembrane signalling. When mammalian HEK293 cells were transfected with $\alpha_{2}$-adrenergic receptors (which generally inhibit adenylyl cyclase activity via $G_{i}$ proteins), the receptors were found to mediate inhibition of synthesis of cyclic AMP in response to appropriate agonists. However, co-transfection with type II adenylyl cyclase converted this response to stimulation of cAMP synthesis. That this stimulation was indeed mediated by $\beta \gamma$ subunits of the $\mathrm{G}_{\mathrm{i}}$ proteins was confirmed by its blockade following pertussis toxin treatment and by cotransfection with the $\alpha$-subunit of transducin which 'scavenges' $\beta \gamma$ subunits but which cannot modulate adenylyl cyclase activity itself. In accord with the findings of Tang and Gilman ${ }^{2}$, stimulation of cAMP synthesis by the $\mathrm{G}_{\mathrm{i}}$-coupled receptors required concurrent activation by $\alpha_{\mathrm{s}}$.

Taken together, these observations suggest that $\beta \gamma$ has a previously unappreciated signalling function, that of a 'conditional' activator of cAMP synthesis. But do they have any physiological relevance? Both groups point to previously confusing results in the literature which are rationalized by this new view of events. These results concern examples of agents which, while not themselves activators of adenylyl cyclase in brain slices (for example glutamate, $\alpha$ adrenergic receptor agonists, $\mathrm{GABA}_{\mathrm{B}}$ receptor agonists), are nonetheless able to potentiate compounds such as histamine, $\beta$-adrenergic agonists or adenosine ${ }^{12}$. These effects, it is now proposed, are due to release of $\beta \gamma$ from $\mathrm{G}_{\mathrm{i}^{-}}$or $\mathrm{G}_{\mathrm{o}}$-type $\mathrm{G}$ proteins which then stimulate a type II adenylyl cyclase.

As Federman et al. say, the presence of multiple effector adenylyl cyclases significantly extends the range and versatility of G-protein-coupled receptor signalling and opens a variety of lines of 'cross-talk' between such systems. But if essentially all G-protein-coupled receptors are capable of modulating the activity of the adenylyl cyclase pathway in a particular cell containing the type II enzyme, requisite physiological precision and specificity might be lost. This raises the provocative issue of whether there are any specificity constraints built in.

Although the number of G-protein $\alpha$-subunits discovered to date by molecular cloning stands at about 20 , it is only quite recently that the diversity of $\beta$ and $\gamma$ subunits has been appreciated (four forms of each cloned thus far). Might they differ in their functional attributes? It is in this context that the paper by Kleuss et al. ${ }^{4}$ is particularly relevant and intriguing. These investigators used somatostatin and muscarinic cholinergic receptor-mediated inhibition of $\mathrm{Ca}^{2+}$ currents in rat pituitary $\mathrm{GH}_{3}$ cells, and nuclear microinjection of short, selective antisense oligonucleotides directed at four distinct $\mathrm{G}$-protein $\beta$ subunits, to clarify whether there is differential involvement of the subunits in coupling the two different receptors to the same effector system. Their data indicate that $\beta_{1}$ is involved in somatostatin receptor signalling, $\beta_{3}$ in muscarinic cholinergic receptor signalling and $\beta_{2}$ and $\beta_{4}$ in neither. Thus, different $\beta \gamma$ subunits seem to be contained within the heterotrimeric $\mathrm{G}$ proteins interacting with these two $\mathrm{G}_{\mathrm{o}}$-coupled receptors. The contribution, if any, of different $\gamma$ subunits remains to be seen.

If stimulation of different receptors leads to the release of distinct populations of $\beta \gamma$, then there is the potential for receptor specificity in the effector functions of $\beta \gamma$ such as stimulation of the type II adenylyl cyclase. This would simply require that the different $\beta \gamma$ isoforms have distinct functional properties with respect to effector stimulation. Whether there are indeed such differences in the ability of different $\beta \gamma$ isoforms to activate adenylyl cyclase is a hot question. Equally provocative are such issues as whether other effectors are regulated by $\beta \gamma$ (for example various phospholipases) and what the underlying molecular mechanisms of such effects might be.

Robert J. Lefkowitz is in the Howard Hughes Medical Institute Research Laboratories, Duke University Medical Center, Durham, North Carolina 27710, USA.

1. Bourne, H. R., Sanders, D. A. \& McCormick, F. Nature 348, 125-132 (1990).

2. Tang, W. J. \& Gilman, A. G. Science 254, 1500-1503 (1991)

3. Federman, A. D., Conklin, B. R., Schrader, K. A., Reed R. R. \& Bourne, H. R. Nature 356, $159-161$ (1992).

4. Kleuss, C., Scherübl, H., Hescheler, J., Schultz, G. \& Wittig, B. Nature 358, $424-426$ (1992).

5. Gilman, A. G. A. Rev. Biochem. 56, 615-649 (1987).

6. Stryer, L. \& Bourne, H. R. A. Rev. Cell Biol. 2, 391-419 (1986)

Bourne, H. R. Nature 337, 504-505 (1989)

8. Krupinski, J. et al. Science 244, 1558-1564 (1989)

9. Feinstein, P. G. et al. Proc. natn. Acad. Sci. U.S.A. 88 10173-10177 (1991).

10. Bakalyar, H. A. \& Reed, R. R. Science 250,1403 1406 (1990).

11. Gao, B. \& Gilman, A. G. Proc. natn. Acad. Sci. U.S.A 88, 10178-10182 (1992)

12. Sattin, A., Rall, T. W. \& Zanella, J. J. Pharmac. exp. Ther. 192, 22-32 (1975) 